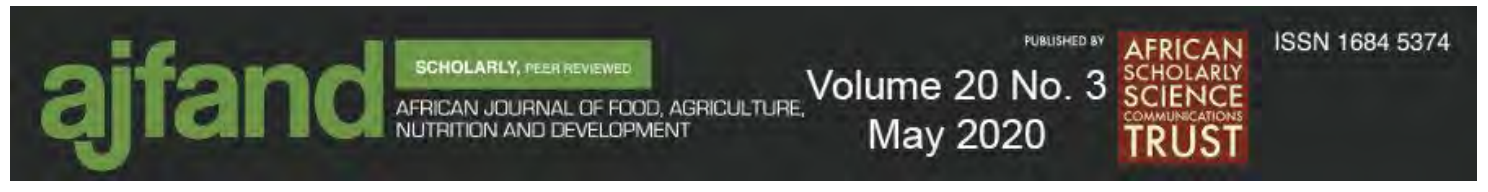

Afr. J. Food Agric. Nutr. Dev. 2020; 20(3):15919-15935

DOI: 10.18697/ajfand.91.18850

\title{
SOCIO-DEMOGRAPHIC DETERMINANTS OF ACCESS TO SANITATION FACILITIES AND WATER IN THE NAMIBIAN RURAL AREAS OF OMAHEKE AND OSHIKOTO REGIONS
}

\section{Mosimane $\mathrm{AW}^{1 *}$ and $\mathrm{JM}_{\mathrm{Kamwi}}{ }^{2}$}

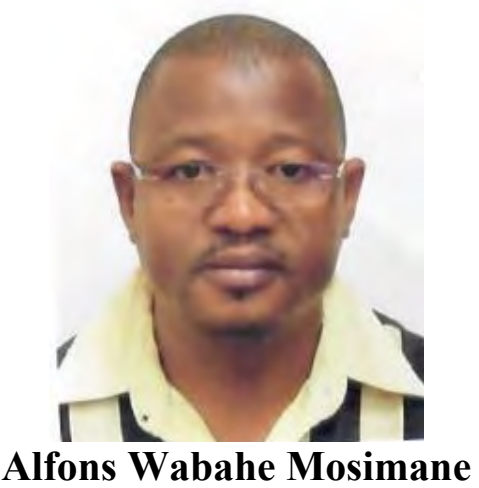

*Corresponding author email: amosimane@unam.na

${ }^{1}$ University of Namibia, Private Bag 13301, Windhoek, Namibia

${ }^{2}$ Namibia University of Science and Technology, Private Bag 13388, Windhoek, Namibia 


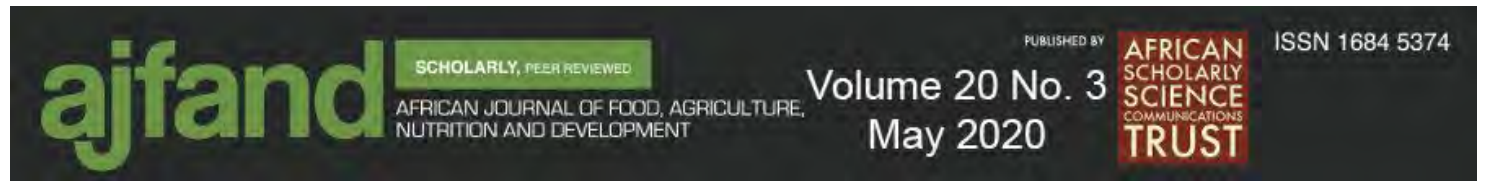

\begin{abstract}
Access to water and sanitation is an important basic need of human beings. However, inadequate access to sanitation facilities and water is a critical challenge in sub-Saharan Africa. The understanding of the socio-demographic factors of rural households to access water and sanitation services across spatio-temporal scales is nascent in developing countries, including Namibia. The present study examines the potential explanatory socio-demographic variables which determine the use of sanitation facilities and access to water in rural communities of Namibia using Omaheke and Oshikoto Regions as case studies. The study was cross-sectional and used quantitative data collection tools. Specifically, the study used structured questionnaires to collect data from 137 households, which were randomly selected in the study regions. Data were entered and analysed using the Statistical Package for Social Sciences (SPSS version 21). The association between the socio-economic data and access to sanitation and water was analysed using the multinomial logistic regression. Pearson's correlation was used to evaluate the correlation between the explanatory variables. The results revealed that there is a significant difference $(\mathrm{p}<0.05)$ in the types of water facilities used in Oshikoto and Omaheke regions. There is no significant influence of gender and age on access to sanitation facilities $(p>0.05)$ in the study areas. Education significantly influenced the choice of piped tap water in the yards $(p<0.05)$ and there was no significant influence of gender, age and education to access other water facilities $(p>0.05)$. The study further found that the reliability (water interruptions) of sanitation and water services and the distance to facilities negatively impacted access to sanitation and water services in the study regions. The study concludes by underscoring the implications of different sociodemographic variables on accessing and accepting various water and sanitation facilities. This analysis enables effective decision making to reconcile the efforts of sustainable development, sanitation and water resource management in Namibia and other countries with a similar set of socio-economic and demographic conditions.
\end{abstract}

Key words: access, sanitation, water, facility, community, management, Oshikoto, Omaheke 


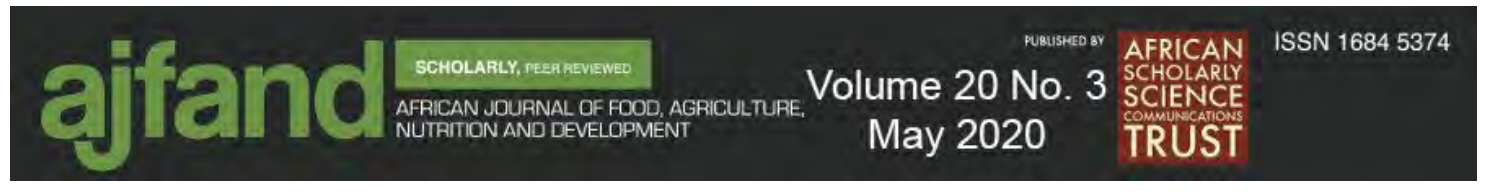

\section{INTRODUCTION}

Access to appropriate and adequate sanitation is fundamental to health, survival, growth and development, and the achievement of Sustainable Development Goals (SDGs). Challenges of access to sanitation and water are severe in sub-Saharan Africa, where the number of people without access to safe water and proper sanitation facilities is increasing due to the prevailing poor socio-economic conditions [1]. Sanitation levels in Africa lag behind the rest of the world because many people live in rural areas [2]. Sanitation, which refers to the maintenance of clean and hygienic conditions in communities, is an indicator of progress [3]. Meeting the SDGs target on sanitation and water is almost impossible because, in most impoverished communities, access to sanitation and water remains dismal unless national governments invest substantial economic resources.

Although access to safe and reliable water is a human right, the availability of water does not necessarily translate to proper sanitation provision in rural areas [4]. Lack of water prevents people from practising hygiene habits, such as washing hands before eating or after using a latrine. Several studies have revealed that improvements in sanitation have been shown to improve health consistently, as indicated by increased child growth, less diarrhoea, reduced parasitic infections, and lower mortality rates $[5,6]$.

Different frameworks are used to assess access to sanitation and water across the world $[7,8]$, using indicators such as water quality, quantity, availability, distribution, affordability, equity and reliability [9]. However, impediments such as insufficient funding for water and sanitation infrastructure, lack of political commitment and goodwill to support the delivery of water and sanitation services, inappropriate technology, lack of local community involvement and limited monitoring of the success and sustainability of water and sanitation programmes has an impact on the indicators [10]. Although the indicators are global, studies must take into account country-specific barriers affecting access to sanitation and water.

Inequalities in access to proper sanitation facilities are also evident in rural and urban areas where households in urban areas (49\%) have improved toilet facilities that are not shared, compared to households in rural areas (17\%). Namibia has the lowest levels of sanitation coverage (34\%) in southern Africa [11]. The majority (70\%) of people in rural areas and $26 \%$ of urban residents defecate in the open, which is harmful to health and hygiene [12]. Open defecation causes hepatitis, polio, diarrhoea, reduced physical growth, worm infestation, cholera and malnutrition. A household has an improved sanitation facility if the toilet is used only by members of one household and if the facility used by the household separates waste from human contact [13]. In Namibia, inadequate sanitation, poor hygiene and unsafe drinking water contribute to $88 \%$ of deaths from diarrhoeal diseases in children [14].

Many studies were conducted on household access to different types of sanitation facilities and factors that influence facility access in developing countries [15]. In Namibia, there are few national studies on access to sanitation facilities and factors that influence the acceptance of facilities used by households [16]. Examining explanatory socio-demographic factors that affect disparity and determine access to household 


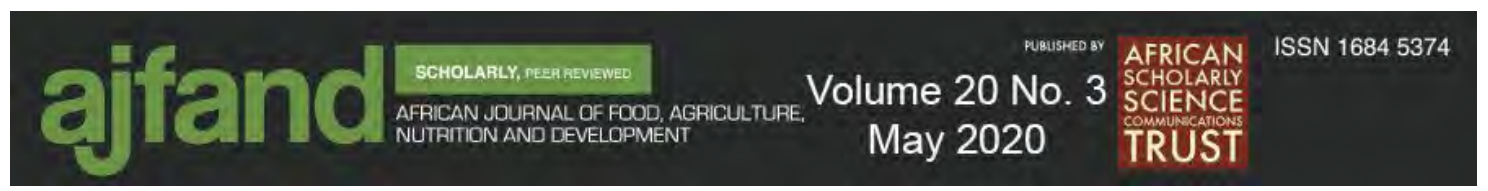

sanitation facilities could help identify and understand areas in the country that need government intervention and assistance. In this study, we examined the explanatory socio-demographic variables, which determine the use of sanitation facilities and access to water in rural communities of Namibia using Omaheke and Oshikoto Regions as case studies. The study will provide information to improve sanitation and water service delivery to the rural communities in Namibia and other areas with similar socioeconomic conditions in developing countries.

\section{MATERIAL AND METHODS}

\section{Study area}

The study was conducted in the rural areas of the Omaheke (Ben-Hur and OreviaAroams) and Oshikoto (Okakoko and Onamulele) regions in 2015/2016 (Figure 1). These areas were selected primarily because they show similar household patterns in terms of access to safe water for drinking and sanitation [17]. Omaheke is located in the East of Namibia and has a population density of 0.8 people per $\mathrm{km}^{2}$ with 6174 households [18]. The main economic activities in Omaheke is commercial and subsistence livestock production. Oshikoto is in the North of Namibia, with a population density of 4.7 people per $\mathrm{km}^{2}$ and 37400 households. The main economic activities in Oshikoto are dryland crop production and subsistence livestock production.

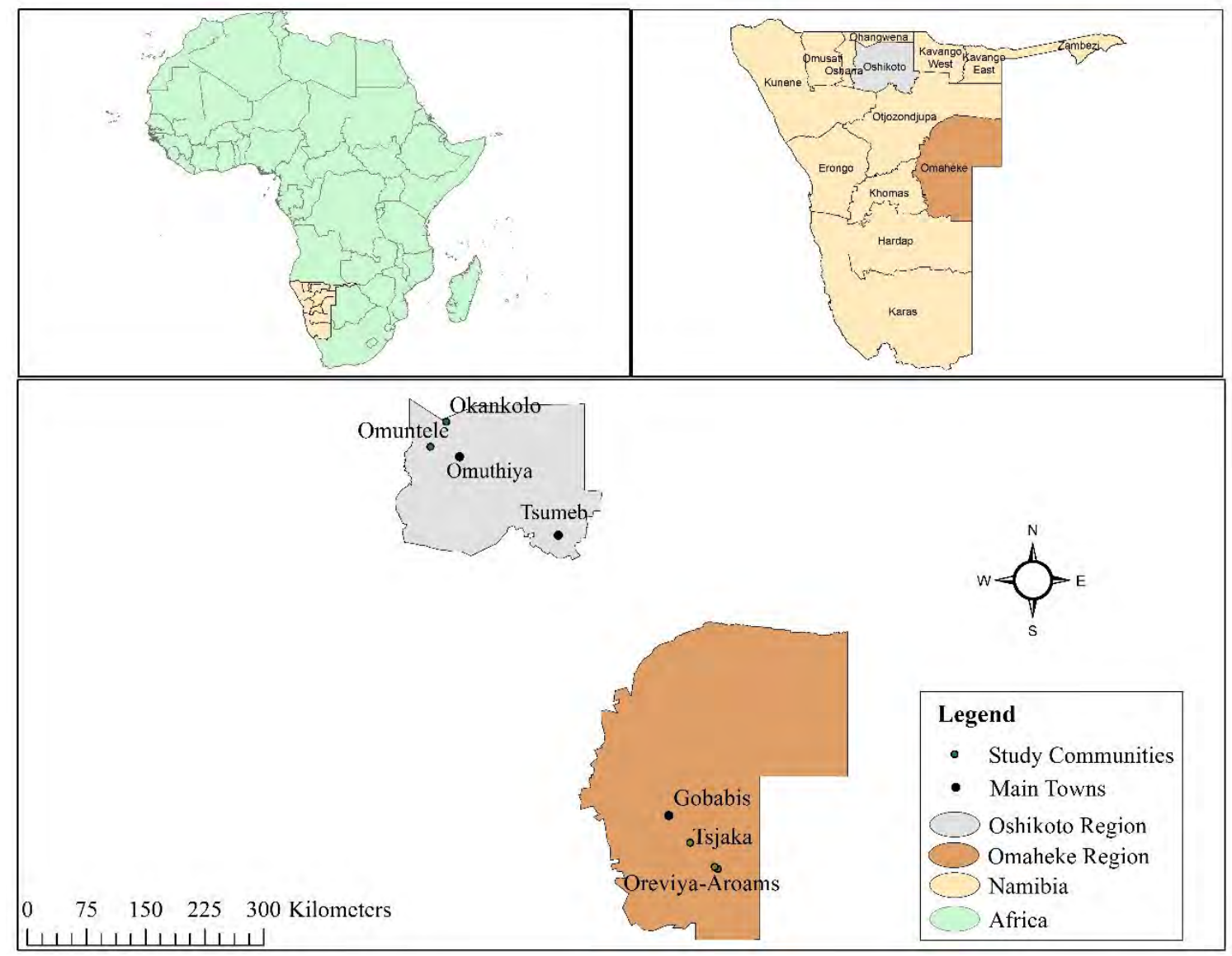

Figure 1: Geographic location of the study areas (own source) 


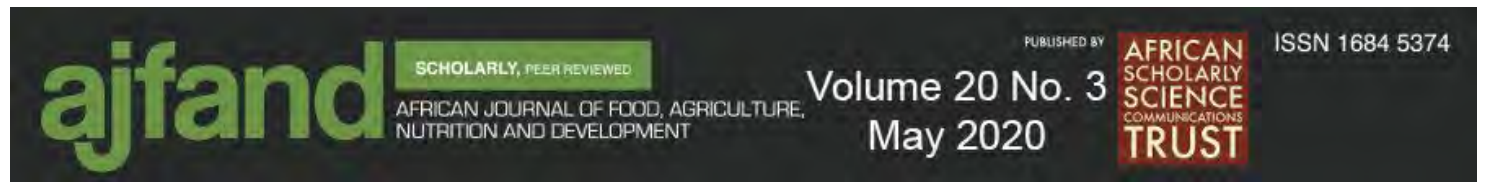

\section{Sampling Technique and Data Collection instruments}

Stratified sampling technique comprising of 137 households were selected and interviewed in the Oshikoto (42) and Omaheke (95) regions. In each household, the household head was the unit of observation. This study defines a household as a group of people living together, making general arrangements for food and other essentials for survival. The study used structured questionnaires to conduct individual interviews with household members. The survey primarily focused on perceived challenges and improvements in sanitation and water access and management, allowing identification of the household's perceptions of water accessibility and available sanitation facilities.

\section{Data analysis and specification of the logistic regression models}

Descriptive statistics were used to describe respondents' socio-economic information, major determinant factors for the perception and attitude of the local communities in the study area on the accessibility to water and sanitation. Further, the study used the Statistical Package for Social Sciences (SPSS version 21) to analyse the quantitative data. Chi-Square statistic was used in defining relationships between study variables to draw relevant conclusions about the population and describe the relationship of different variables with the attitude and perceptions of the local communities about accessibility to water and sanitation. Association between the socio-economic data and access to sanitation and water was analysed using the multinomial logistic regression. The researchers used the estimated odds ratios to measure the magnitude of the strength of association between socio-economic explanatory variables and access to sanitation and water. Socio-economic variables were selected based on their representation of the factors believed to have an impact on the accessibility to water and sanitation facilities in the study areas. A p-value of less than 0.05 was considered to denote a statistically significant association.

To identify the determinants of the household decision to adopt various types of water and sanitation facilities, the researchers assumed that a stable household will choose among the five mutually exclusive sanitation facilities and which offer the maximum utility. For each of the sanitation facilities, the type of sanitation facility was categorised as either equal to 1 if a household had opted for a specific sanitation facility and 0 if that household had not chosen the sanitation facilities option. Similarly, for each of the water sources, accessibility to a specific water source was categorised as either equal to 1 if a household had access to a specific water source and 0 if that household does not have access to that specific water source.

The following explanatory variables were used for assessing access to sanitation and water: (1) gender; (2) age; and (3) education level. In the logistic regression analyses, dummy variables were constructed for these categories with the last category used as a reference. Sanitation facilities used for modelling are: (1) flush toilet connected to a public sewerage system; (2) flush toilet connected to a septic tank; (3) pit latrine/toilet with ventilation pipe; (4) pit latrine/toilet without ventilation pipe; (5) chemical toilets; and (6) bucket toilets. Water facilities (dependent variables) used for modelling are: (1) piped (tap) water in dwelling or house; (2) piped tap water in yard; (3) borehole in yard; (4) neighbours tap; (5) public/ communal tap; (6) water carrier tanker; and (7) borehole outside yard. The researchers were also aware that the predictors may be collinear, which 


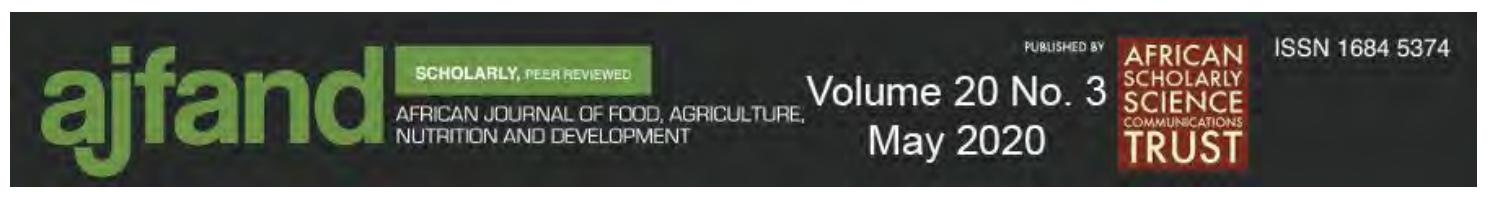

might cause problems in the estimation of regression coefficients. Therefore, Pearson's correlation was used to evaluate the correlation between the explanatory variables.

\section{RESULTS AND DISCUSSION}

\section{Demographic data and trends of accesses to water and sanitation in the Regions}

A total of 42 respondents were interviewed in the Oshikoto region and 95 in the Omaheke region. In terms of gender, $36 \%$ of respondents in the Oshikoto region were male and $64 \%$ female. In the Omaheke region, $54 \%$ of the respondents were male, and 46 were female. In the Oshikoto region, $41 \%$ of respondents were middle-aged, $41 \%$ were older members of society ( 55 years and above), and 18\% were young-aged (18-34 years). In the Omaheke region, most respondents (52\%) were mainly older members of society ( 55 years and above), 43\% were middle-aged (35-54 years), and 5\% were young-aged (1834 years). Regarding education, $92 \%$ of respondents in the Oshikoto region had formal education. On the other hand, $75 \%$ of respondents had formal education in the Omaheke region.

\section{Access to water}

About $100 \%$ of the respondents in the Oshikoto region had access to water compared to $92 \%$ in the Omaheke region (Figure 2).

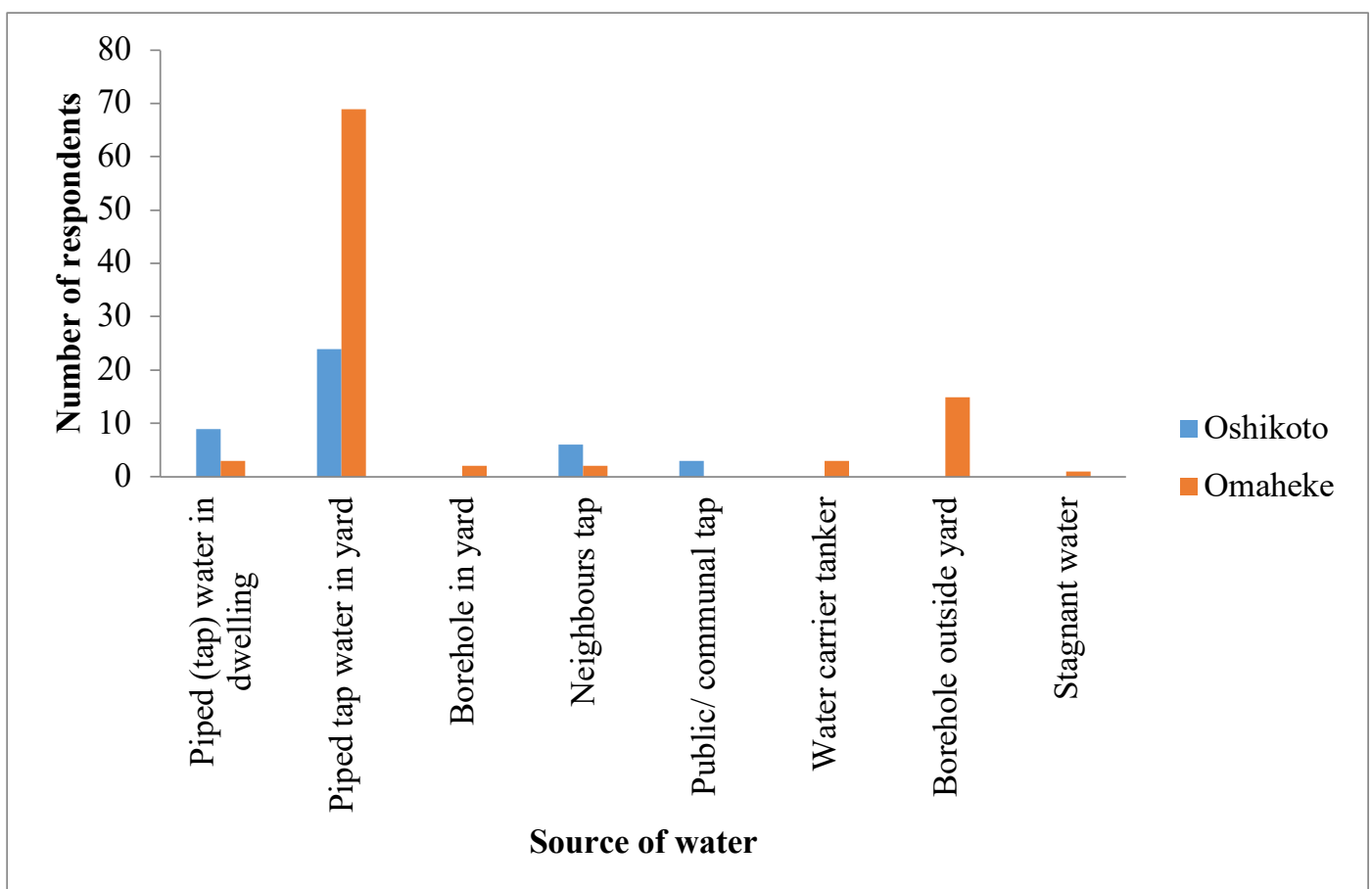

Figure 2: Sources of water by region

In the Oshikoto region, the predominant water source is piped tap water in the yard and piped (tap) water inside the dwelling. In the Omaheke region, the primary water source is piped tap water in the yard and borehole outside the yard. Respondents only reported water carrier tanker, boreholes in the yard, boreholes outside the yard and stagnant water 


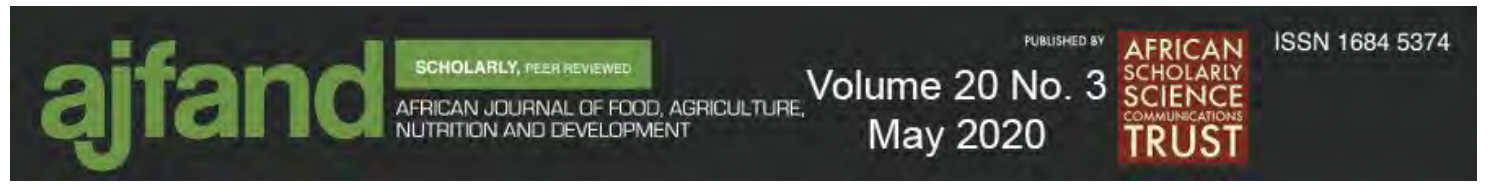

in the Omaheke region. There is a significant difference $(\mathrm{p}<0.05)$ in the types of water facilities used in Oshikoto and Omaheke regions.

\section{Access to sanitation}

About $43 \%$ of respondents in the Oshikoto region had access to sanitation, compared to $78 \%$ in the Omaheke region (Figure 3).

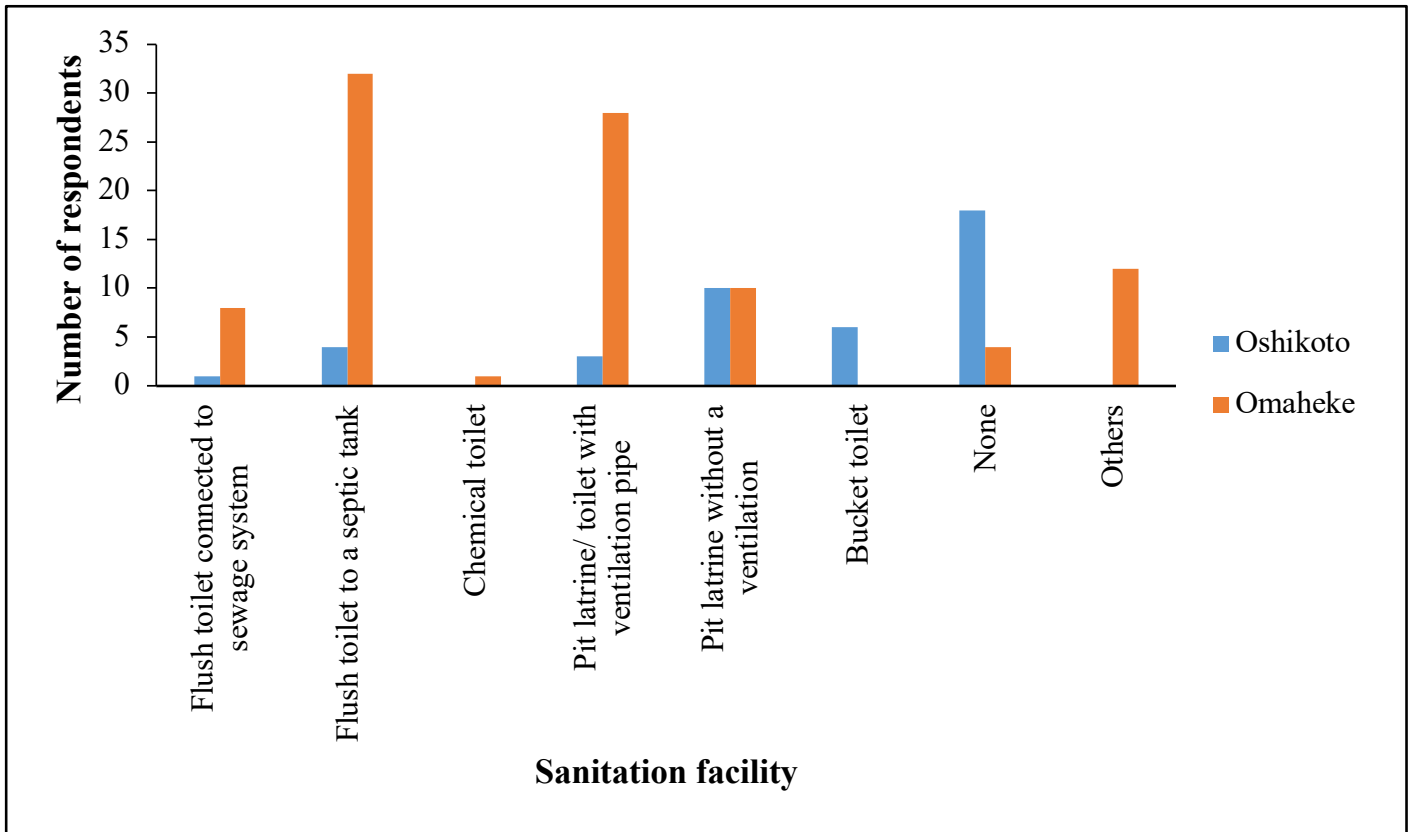

Figure 3: Sanitation facility by region

In the Oshikoto region, most respondents $(57 \%)$ do not have access to any sanitation facilities. However, pit latrine without ventilation and bucket toilets were reported. In the Omaheke region, the predominant sanitation facility is a flush toilet with a septic tank followed by a pit latrine/toilet with ventilation. Chemical toilet and others were only recorded in the Omaheke region while bucket toilets were only recorded in the Oshikoto region. There is a significant difference $(p<0.05)$ in the types of sanitation facilities in Oshikoto and Omaheke regions.

Flush toilets connected to septic tanks and pit latrines with ventilation are the most common and preferred types of sanitation facilities in Omaheke because of limited and unreliable water access and socio-economic wellbeing. However, wealthy households, which can invest in reliable water infrastructure prefer flushing toilet facilities. The construction of facilities that meet the social and economic factors of the households, such as culture, religion and economic capacity is essential when promoting sanitation and water facilities in communities [19].

Education, gender and age influence on access to sanitation and water

Table 1 shows the perceptions of local communities to access water and sanitation facilities. The results revealed that formal education is significantly related to the choice of sanitation facilities used by communities. Formal education plays a central role in 


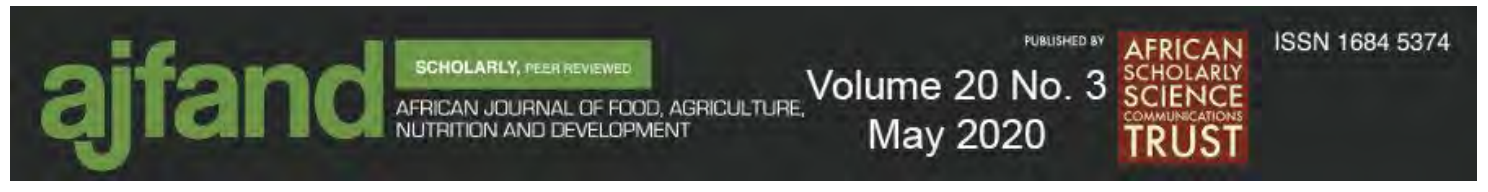

raising public awareness of hygiene and affordability of modern sanitation facilities [20]. In addition, education is regarded as one of the most important contributors to more remunerative salaried and skilled employment in rural Africa [21]. Thus, education paves the way for better-paid job opportunities that require formal schooling. In turn, this may influence the adoption of more hygienic sanitation facilities used by households.

Results of the multinomial logistic analysis of the hypothesised explanatory variables influencing the access of households to sanitation facilities in Oshikoto region are summarised in Table 2. The output of the logistic regression model revealed that after adjusting for the effect of the factors, there is a significant influence of education on pit latrine toilet without ventilation pipe facilities $(\mathrm{p}<0.05)$. A high education level is directly related to the use of modern sanitation facilities (flush to sewer or septic tanks), while a lower education level is related to the use of pit latrines and crude facilities [22]. Other studies have further shown that the better the level of education, the better the socioeconomic wellbeing of the household [23]. According to the empirical results, wealth has a substantial and significant positive impact on the chances of having access to sanitation facilities. As espoused by Montgomery et al. [24], more affluent individuals are, therefore, expected to have more access to sanitation and water services. Results of the model revealed that there is no significant influence of gender and age on access to sanitation facilities $(\mathrm{p}>0.05)$.

Although access to flush toilets and access to water shows evidence of improved hygiene in Namibia, pit latrine remains the most commonly used sanitation facilities in the study areas. The health benefits of pit latrines, if correctly built, used and maintained are not different from flushing toilets and should, therefore, be encouraged due to low costs of infrastructure development [25]. Community involvement and gender equity in decisionmaking may enhance the efficiency of pit latrines in communities [24].

The results shown in Table 3 illustrate the multinomial logistic analysis of the hypothesised explanatory variables influencing the access of households to water facilities. The output of the logistic regression model revealed that after adjusting for the effect of the factors, education significantly influenced the choice of piped tap water in the yards $(\mathrm{p}<0.05)$. Results of the model revealed that there is no significant influence of gender, age and education to access other water facilities $(\mathrm{p}>0.05)$.

The findings of this study show that the type of sanitation facility communities employ is based on affordability and the social-economic status of the respondents. Some community members cannot afford to invest in water infrastructure (pipes) to bring water to their homes and resort to accessing water from public/communal taps or neighbours. The study confirms the findings by Sigenu [26], who indicated that people with the lowest socio-economic status in the social hierarchy often suffer disproportionately when water supplies are limited. Evidence suggests that access to water, as well as practising hygiene habits can improve the health of communities [27].

\section{Reliability and distance to water and sanitation services}

Although no significant association between the length of water disruption and demographic factors was found $(\mathrm{p}>0.05)$, prolonged shortage of piped water supply 


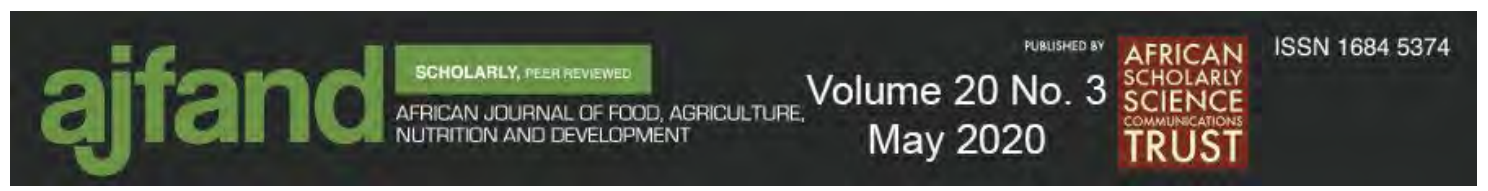

being experienced in the study areas grossly undermines the use of modern sanitation facilities. In that case, communities always strive to improve water facilities within their economic means by investing resources in building the facilities. Two factors impact access to sanitation and water services in Namibia, namely (1) the reliability (water interruptions) of sanitation and water services and (2) the distance to facilities. Reliable water supply refers to availability and access to good quality and quantity of water to meet the needs of communities.

Access to water can be unreliable and variable by season, year and location, which has an impact on access to sanitation. The present study acknowledges that there are numerous definitions of reliable water supply, but the emphasis is on communities' unlimited access to sanitation and water services. Several factors affect the reliability of water supply, but the most common is the distribution system of water to households. The problem of water distribution is prevalent in developing countries due to insufficient resources for the maintenance of the water distribution system infrastructure [28]. The length of water interruptions in communities determines the severity of impacts on the community.

Water reliability in Namibia and many other developing countries is due to water supply interruption, which makes it difficult for sanitation facilities to function and for communities to observe hygiene. There were significant differences in the reasons for the water interruptions in the two areas studied $(\mathrm{p}<0.05)$.

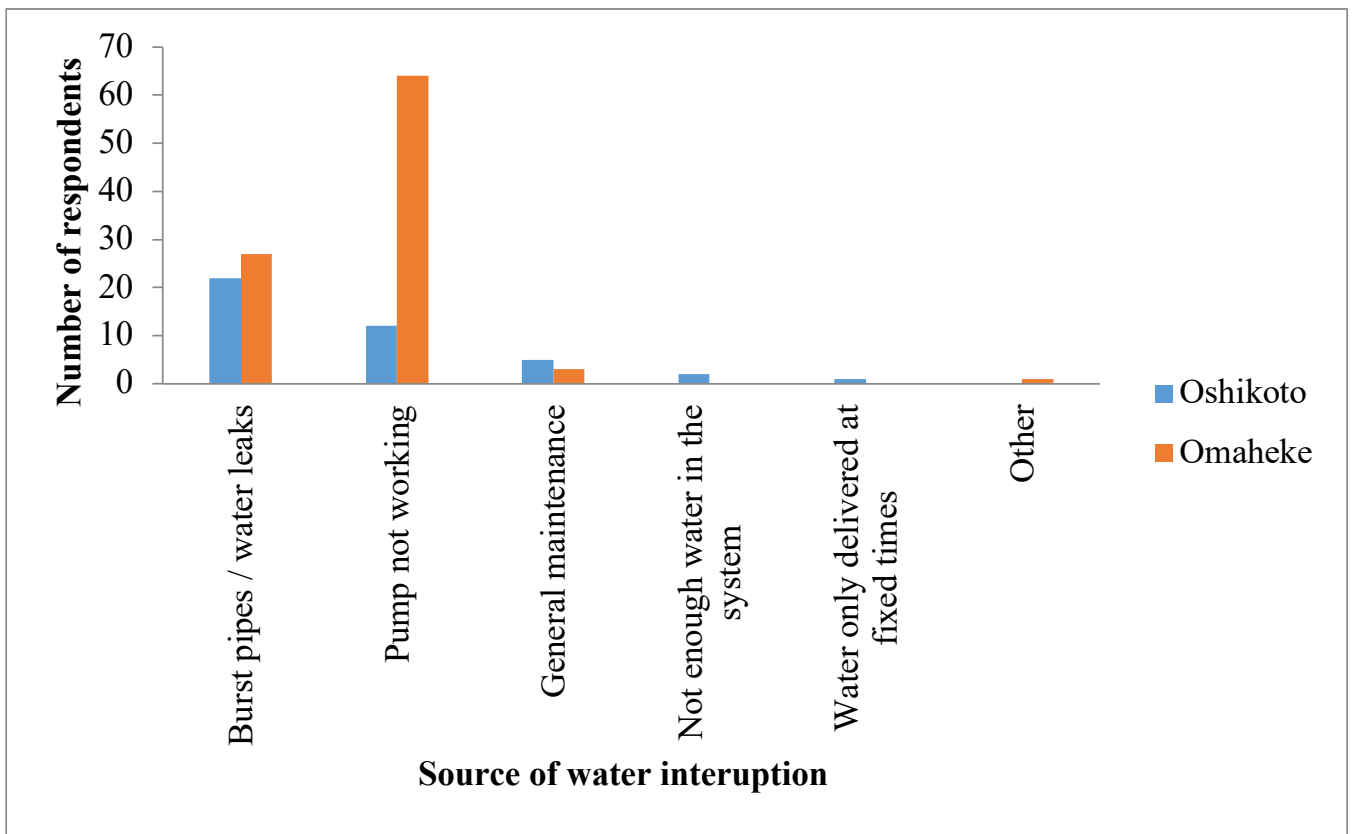

Figure 4: Source of water interruption by region

As can be seen in Figure 4, burst pipes and pumps not working were cited as the leading causes of the disruptions by respondents in the Oshikoto region. In the Omaheke region, the most common cause of water supply interruptions is a non-functioning pump. One respondent in the Omaheke region explained that "we are never even consulted about the eminent interruptions. I would hear my wife yelling at children to collect the last drops 


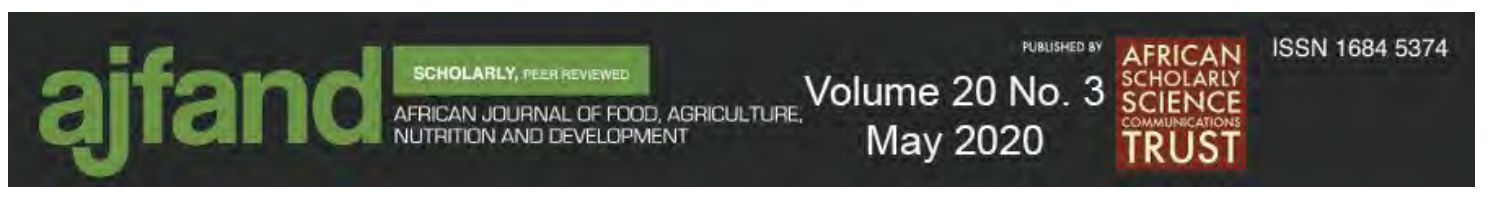

of water from the tap." The findings emphasise the need for infrastructure maintenance and management to ensure water availability.

When assessing access to sanitation, the variability of water supplies is often ignored. In Namibia, variability in water supply systems is linked to water interruptions due to unreliable water infrastructure. Ageing, inadequate, under-funded or poorly maintained sanitation and water infrastructure is often a critical factor leading to uncertain availability, in public communities [23]. Technical problems associated with the operation and maintenance of water infrastructure are the causes of water interruptions. Support services to communities concerning operation and maintenance and availability of working tools (vehicles and parts) compromise access to sanitation and water. Appropriate skills and competencies define the ability to manage water and sanitation infrastructure and provide a reliable water supply. The skills are needed at the community, regional and national levels to support the implementation of government policies regarding the provision of sanitation and water services in rural areas [23]. Closer government and community partnership, where community members are trained to acquire the necessary skills could contribute to improved sanitation and water services.

\section{Distance to access water}

There is a significant difference in the distance to access water in Oshikoto and Omaheke regions $(\mathrm{p}<0.05)$. Most respondents $(69 \%)$ in Oshikoto have access to water in their homes, followed by $14 \%$ of the respondents whose water sources are less than 200 meters away. In the Omaheke region, most respondents (40\%) have access to water outside their houses but inside their yards, followed by $29 \%$ of respondents with water inside their homes.

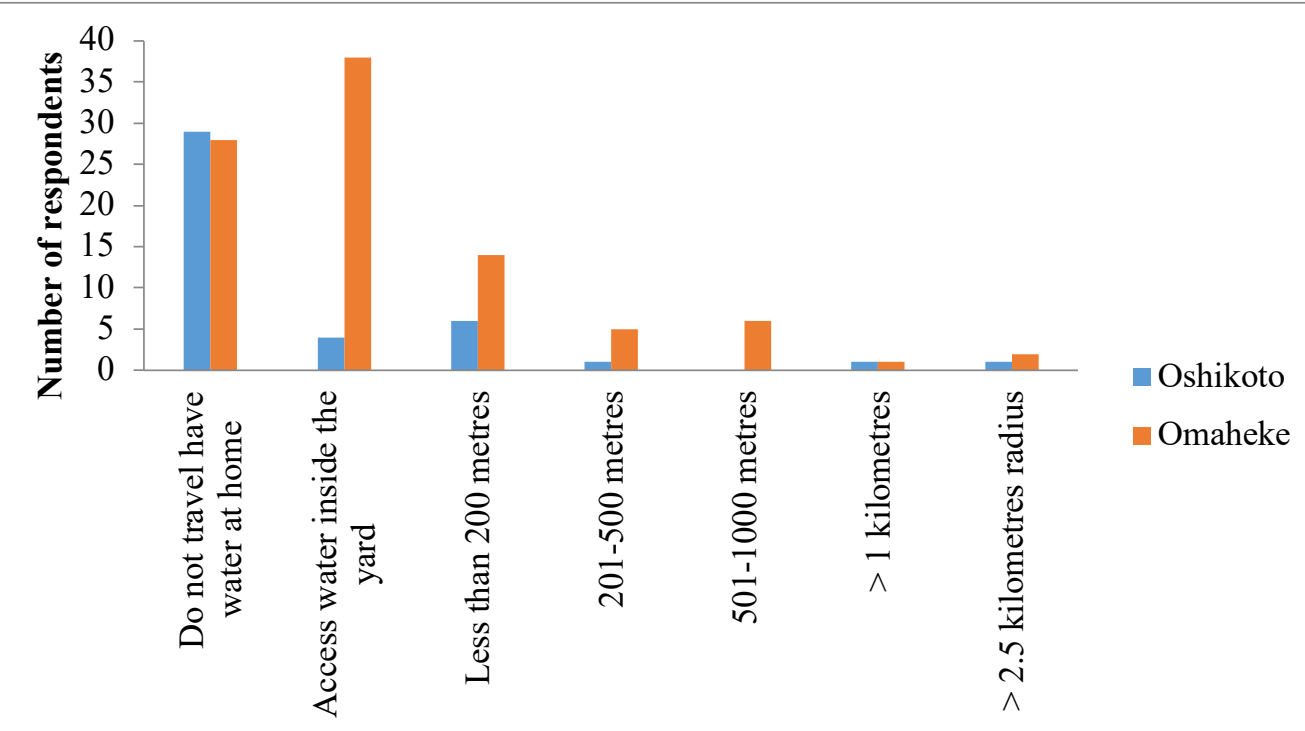

Distance to collect water

\section{Figure 5: Distance to collect water by region}

Distance to sanitation and water facilities affects the accessibility of the service to the users. The amount of time spent collecting water is a significant determining factor in 


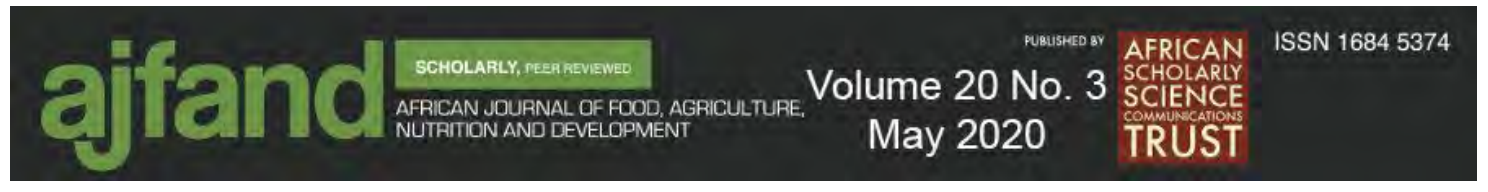

access to water [23]. Distance to facilities results in inequities in access to proper sanitation and water facilities, particularly in rural in comparison to urban areas.

Longer distances to sanitation and water supply contribute to inadequate access because much time is lost when collecting water. Therefore, the value of time communities lost seeking access to water justifies the need to invest in water supply. Household connection to water distribution systems contributes to better practices of hygiene, which improves health benefits and minimizes the search for a place to defecate. The study shows that insufficient access to both sanitation and water is common in the Oshikoto region. The majority of people in rural areas defecate in the open due to lack of alternative facilities, a practice that is harmful to health.

\section{Involvement of communities}

Communities play a critical role in improving sanitation and changing sanitation habits that save lives. Research in Namibia showed that communities are not adequately involved in improving sanitation in rural areas, notwithstanding the presence of the National Sanitation Strategy that encourages community participation. The involvement of government in the community was only observed through the provision of sanitation and water infrastructure, as community members could not define the role of government concerning the information they provided to communities. Before review of the sanitation strategy, sanitation in Namibia was characterised by limited coordination as government at local and national level operated independently and in isolation [29]. In both Omaheke and Oshikoto regions, communities used different types of sanitation facilities due to lack of information and awareness about sanitation facilities and hygiene in the community. In the past years, unlike water supply, sanitation in Namibia was a mandate shared by several government offices, a situation which has resulted in a fragmented approach to service delivery to communities.

For years, there was no enabling policy environment through which various stakeholders could clearly understand their roles and responsibilities, with no adequate coordination mechanism and harmonisation of policies, regulations and guidelines [29]. In response, critical strategic issues were identified and highlighted in the strategy to counter the problems and seize development prospects. Water Supply and Sanitation (WATSAN) sector coordination is placed in the Ministry of Agriculture, Water and Forestry (MAWF), which created an enabling environment for the management and implementation of the sanitation strategy. The coordination, further, started the process of building good relations and partnerships in the water supply and sanitation sector through coordination at both national and regional levels [29]. The findings demonstrate that governance structure and their mandates are fundamental in providing and improving access to sanitation in rural communities.

In Namibia, like in many developing countries, there is a need to change the way issues of sanitation are being communicated to communities to impact behavioural change by engaging communities as partners to change their behaviour. The dissemination of hygiene and sanitation promotion activities in Namibia were based mainly on sharing health information, but this has proved not to deliver sustainable hygiene behaviour change [29]. The partnerships between the community, government, non-governmental organisations (NGOs) and community-based organisations (CBOs) facilitate a better 


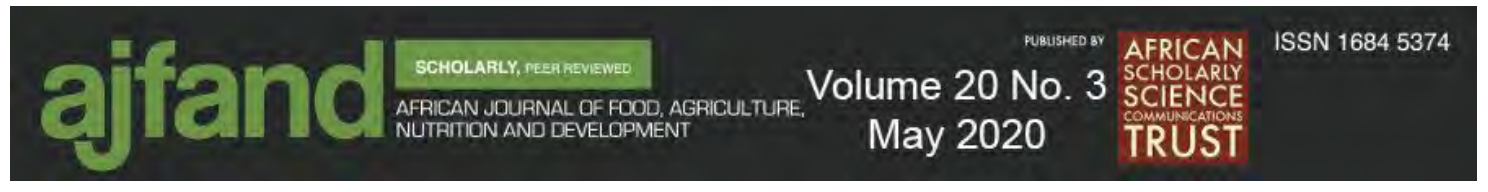

impact in changing the behaviour of communities [30]. The increasing community knowledge and understanding of sanitation and its linkages to health created the demand for improved services and may result in behaviour changes. Many other important factors determine access to sanitation and water, and that might impact the success of sanitation programmes implementation, which was not part of this study.

\section{CONCLUSION}

This study examined explanatory socio-demographic factors determining access to sanitation and water services in rural communities. This study contributes to the ongoing discourse of improving access to sanitation and water in rural areas of developing countries. Valuable insight from the research is the influence of socioeconomic factors, reliability, distance, and involvement of communities in the provision of sanitation and water services in rural Namibia. This study shows that communities always strive to improve access to sanitation and water facilities by investing resources. The results show that water reliability and variability influence access to sanitation in rural communities. This study indicates that distance to sanitation and water facilities influence access to the services and contributes to inadequate access because much time is lost when collecting water or looking for a defecation place. The unique characteristics of each region, its people and their socio-economic challenges, and differences in vegetation, climate and topography are the possible reasons for the variation in the type of facilities household used in Oshikoto and Omaheke regions.

Community-based management to scaling up sanitation programmes could improve the success rate when the government and other agencies provide appropriate support and recognition to community involvement. Such involvement should be based on a clear policy, which is premised on the rights of all people to determine their future. Government attention should focus on local institutional and capacity building to provide the necessary expertise and skills for communities to manage sanitation and water facilities.

Finally, the study highlighted socio-demographic factors determining access to sanitation and water that if considered in the implementation of sanitation programmes can potentially increase the success rate when sanitation is scaled up in rural communities of Namibia. Access to sanitation and water could be further improved through a combination of empirical research and monitoring to understand existing disparities and measure progress, explicitly whether the improvements are reaching the rural communities and the poor. When communities have a clear view of the problem and are inspired and involved, some of the main sanitation and water problems can be solved by seeking home-grown and sustainable solutions.

\section{ACKNOWLEDGEMENTS}

We want to extend our appreciation to the National Commission for Research Science and Technology (NCRST) in Namibia, for funding this study. The University of Namibia managed the funds. Special thanks go to all the respondents who participated in the survey and interviews for their willingness and time. The funding source had no involvement in the study design, collection, analysis, interpretation of data, writing or submission of the article for publication. 


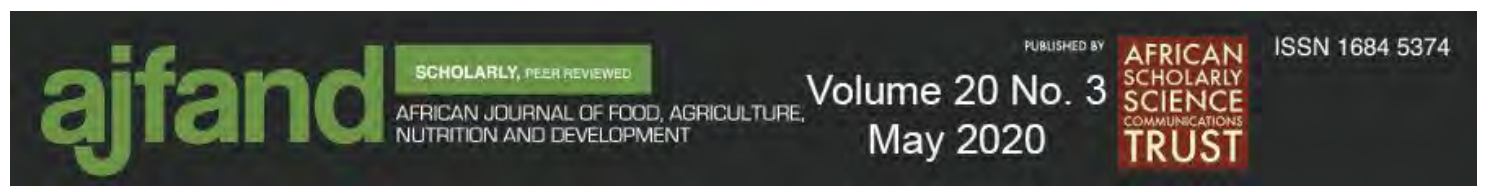

Table 1: Perceptions of local communities on accessibility to water and sanitation

\begin{tabular}{|llc|}
\hline Variables & & $\chi^{2}$ \\
\hline \multirow{5}{*}{ Gender } & Access to water & 0.143 \\
& Source of water & 0.391 \\
& Access to sanitation & 0.441 \\
& Types of sanitation facilities & 0.315 \\
& Distance to collect water & 0.512 \\
& Participation in activities of the CBM & 0.821 \\
\hline \multirow{4}{*}{ Age } & Access to water & 0.926 \\
& Source of water & 0.277 \\
& Access to sanitation & 0.416 \\
& Types of sanitation facilities & 0.120 \\
& Distance to collect water & 0.826 \\
& Participation in activities of the CBM & 0.111 \\
\hline \multirow{3}{*}{ Education } & Access to water & 0.421 \\
& Source of water & 0.986 \\
& Access to sanitation & 0.157 \\
& Types of sanitation facilities & $\mathbf{0 . 0 2 7}$ \\
& Distance to collect water & 0.702 \\
& Participation in activities of the CBM & 0.222 \\
\hline
\end{tabular}




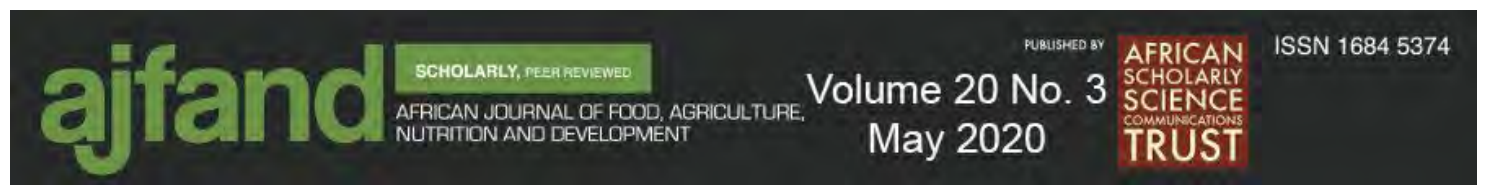

Table 2: Factors affecting access of households to sanitation facilities

\begin{tabular}{|llrrrr|}
\hline Sanitation facility & $\begin{array}{l}\text { Independent } \\
\text { variables }\end{array}$ & p-value & Odds ratio & Lower & Upper \\
\hline \multirow{3}{*}{ Flush toilet connected } & Gender & 0.814 & 0.837 & 0.189 & 3.698 \\
to a septic tank & Age & 0.896 & 1.088 & 0.305 & 3.883 \\
& Education & 0.734 & 1.137 & 0.543 & 2.379 \\
\hline Chemical toilet & Gender & 0.998 & 1.187 & 0.555 & 2.231 \\
\hline \multirow{3}{*}{ Pit latrine toilet with } & Age & 0.912 & 1.085 & 0.22 & 4.221 \\
ventilation pipe & Education & 0.848 & 1.177 & 0.223 & 6.199 \\
\hline Pit latrine toilet & Gge & 0.529 & 0.610 & 0.131 & 2.845 \\
without ventilation & Education & 0.329 & 0.524 & 0.144 & 1.915 \\
pipe & Gender & 0.084 & 1.937 & 0.915 & 4.102 \\
\hline & Age & 0.550 & 1.657 & 0.317 & 8.673 \\
& Education & $\mathbf{0 . 0 3 9}$ & 0.694 & 0.171 & 2.813 \\
Bucket toilet & Gender & 0.836 & 0.800 & 0.096 & 6.630 \\
\hline & Age & 0.326 & 0.426 & 0.077 & 2.340 \\
& Education & 0.538 & 1.385 & 0.491 & 3.908 \\
\hline None & Gender & 0.270 & 2.587 & 0.477 & 14.032 \\
\hline & Age & 0.059 & 0.270 & 0.070 & 1.049 \\
& Education & 0.056 & 2.198 & 0.982 & 4.921 \\
\hline Others & Gender & 0.680 & 0.688 & 0.116 & 4.076 \\
& Age & 0.918 & 1.086 & 0.228 & 5.166 \\
& Education & 0.229 & 1.664 & 0.725 & 3.818 \\
\hline
\end{tabular}

The reference category is none - significance level 0.05

Table 3: Factors affecting access of households to water facilities

\begin{tabular}{|llrrrr|}
\hline \multirow{2}{*}{ Source of water } & Independent & & & & \\
\hline \multirow{2}{*}{$\begin{array}{l}\text { Pariables } \\
\text { yard }\end{array}$} & Gender & p-value & Odds ratio & Lower & Upper \\
\hline \multirow{3}{*}{ Neighbours tap } & Age & 0.105 & 2.967 & 0.797 & 11.050 \\
& Education & 0.227 & 0.502 & 0.164 & 1.536 \\
& Gender & 0.043 & 1.874 & 1.021 & 3.439 \\
\hline \multirow{4}{*}{ Borehole outside yard } & Age & 0.339 & 2.530 & 0.377 & 16.981 \\
& Education & 0.471 & 0.556 & 0.113 & 2.741 \\
& Gender & 0.054 & 2.253 & 0.987 & 5.142 \\
\hline \multirow{3}{*}{ Others } & Education & 0.461 & 1.851 & 0.360 & 9.522 \\
& Gender & 0.054 & 0.277 & 0.075 & 1.021 \\
& Age & 0.072 & 1.972 & 0.942 & 4.129 \\
\hline
\end{tabular}

The reference category is piped (tap) water in dwelling or house - significance level 0.05 


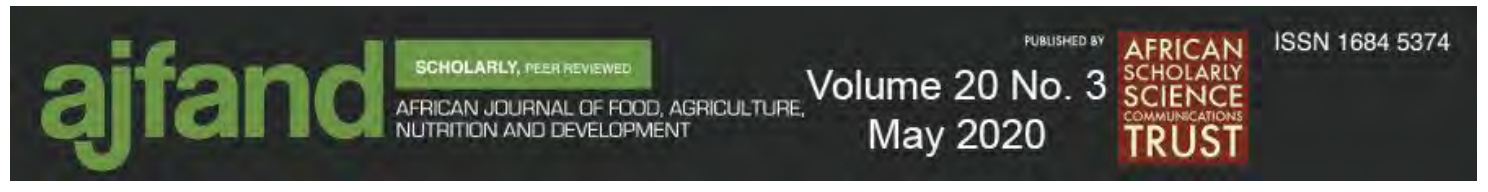

\section{REFERENCES}

1. WHO. Meeting the MDG drinking water and sanitation target: the urban and rural challenge of the decade. Geneva, Switzerland: WHO Press, 2006.

2. UNICEF and WHO. Progress on drinking water and sanitation. Special focus on sanitation. Geneva, Switzerland: WHO, 2008.

3. EPA's 2007 report on the environment: Science report (Science Advisory Board's (SAB) Review draft). Washington, DC: Office of Research and Development, U.S. Environmental Protection Agency, 2007.

4. Corcoran E Sick water?: the central role of wastewater management in sustainable development: a rapid response assessment. UNEP/Earth print, 2010.

5. Haffejee F, Chopra M and D Sanders The problem of handwashing and paying for water in South Africa. Cape Town: Municipal Services Project Occasional Paper No 13. The University of Western Cape, 2007.

6. Mufune P and K Matengu Concept paper on Sanitation and Hygiene. Windhoek, Namibia: Ministry of Information and Broadcasting, 2009.

7. WHO. Guidelines for drinking water quality: Surveillance and control of community supplies. Geneva, Switzerland, 1997, Volume 3.

8. UNICEF and WHO. Progress on drinking water and sanitation. Special focus on sanitation. Geneva, Switzerland: WHO, 2008.

9. Moe CL and RD Rheingans Global challenges in water, sanitation and health. Journal of Water and Health. 2006; 4(S1):41-57.

10. Kayser GM Domestic water service delivery indicators and frameworks for monitoring, evaluation, policy and planning: a review. International Journal of Environmental Research and Public Health. 2013; 10(10): 4812-4835.

11. UNICEF. A Namibia fit for children: Sanitation. Windhoek: UNICEF, 2015.

12. NSA. Namibia Inter-censal Demographic Survey 2016 Report. Windhoek, Namibia: Namibia Statistics Agency, 2017.

13. WHO and UNICEF. Joint Monitoring Programme (JMP) for Water Supply and Sanitation. Progress on Drinking Water and Sanitation. Geneva and New York: WHO/UNICEF, 2012.

14. GRN. Achieving the Millennium Development Goals through facts, insights and action: A guide for Namibia's parliamentarians. Windhoek, Namibia: Government of the Republic of Namibia, 2015. 


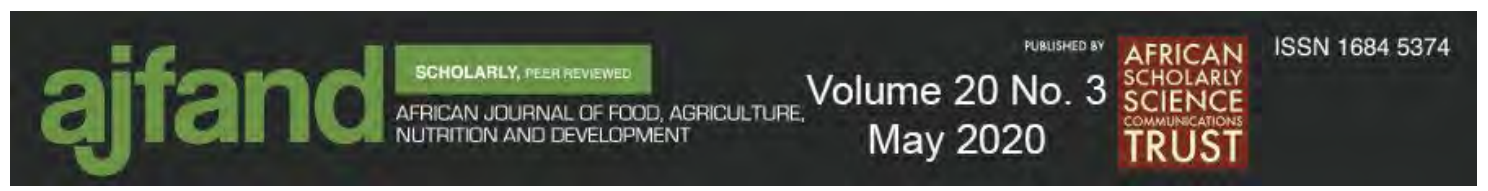

15. Adams EA Socioeconomic and demographic predictors of potable water and sanitation access in Ghana. Social Indicators Research. 2016;126(2): 673-687.

16. Matengu $\mathbf{K}$ Towards improving rural water supply and sanitation coverage in Caprivi, North-east Namibia. Journal for Studies in Humanities \& Social Sciences. $2013 ; 21-33$.

17. NSA. Namibia Inter-censal Demographic Survey 2016 Report. Windhoek, Namibia: Namibia Statistics Agency, 2017.

18. NSA. Namibia 2011 Population and Housing Census Main Report. Windhoek, Namibia: Namibia Statistics Agency, 2011.

19. Hendriksen A, Tukahirwa J, Oosterveer PJ and AP Mol Participatory decision making for sanitation improvements in unplanned urban settlements in East Africa. The Journal of Environment \& Development. 2012; 21(1):98-119.

20. Diduck A Critical education in resource and environmental management: learning and empowerment for a sustainable future. Journal of Environmental Management. 1999; 57(2): 85-97.

21. Barrett $\mathbf{C B}$, Reardon $\mathbf{T}$ and $\mathbf{P}$ Webb Nonfarm income diversification and household livelihood strategies in rural Africa: concepts, dynamics, and policy implications. Food policy. 2001; 26(4): 315-331.

22. Abubakar IR Access to sanitation facilities among Nigerian households: determinants and sustainability implications. Sustainability. 2017; 9(4):547.

23. Sullivan C, Meigh J, Giacomello A, Fediw T, Lawrence $\mathbf{P}$ and M Samad The Water Poverty Index: Development and application at the community scale. Natural Resources Forum 27, 189-199, 2003.

24. Montgomery M, Bartram $\mathbf{J}$ and $\mathbf{M}$ Elimelech Increasing Functional Sustainability of Water and Sanitation Supplies. Environmental Engineering Science. 2009; 26 (5): 1017-1023.

25. Bartram $\mathbf{J}$ and $\mathbf{S}$ Cairncross Hygiene, sanitation, and water: forgotten foundations of health. PLoS medicine. 2010; 7(11) e1000367.

26. Sigenu K The role of rural women in mitigating water scarcity. Bloemfontein: University of the Free State, 2006.

27. Pan S, Armitage $\mathbf{N}$ and $\mathbf{M}$ Ryneveld Assessing equity: a way to improve sanitation service delivery in South African informal settlements. Journal of Water, Sanitation and Hygiene Development. 2018; 429-438.

28. GWP. Towards Water Security: A Framework for Action. Sweden, Stockholm: Global Water Partnership, 2000. 


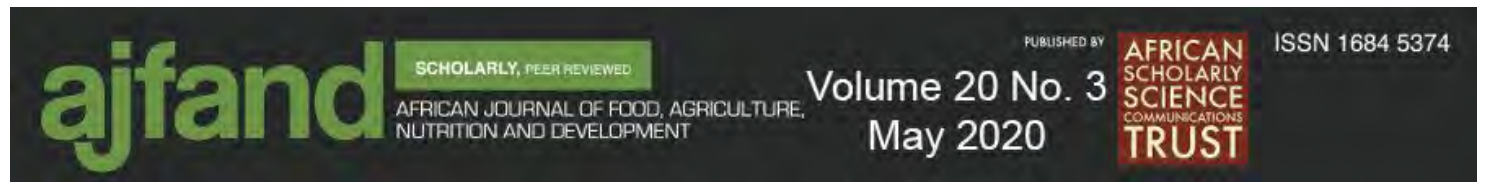

29. MAWF. Namibia's National Sanitation Strategy for 2010 to 2015. Windhoek, Namibia: Ministry of Agriculture, Water and Forestry, Republic of Namibia, 2010.

30. Tukahirwa JT, Mol AP and P Oosterveer Access of urban poor to NGO/CBOsupplied sanitation and solid waste services in Uganda: The role of social proximity. Habitat International. 2011; 35(4):582-591. 